reticulum. ${ }^{810}$ Light microscopy ${ }^{11}$ shows no changes that might not occur in other cardiomyopathies; macroscopically, the heart is dilated and hypertrophied.

Invasive studies of the heart in alcoholics ${ }^{12}{ }^{13}$ have shown depression of left ventricular function and reduced cardiac output, while echocardiography has since provided a useful means of non-invasive study of alcoholics both with and without symptoms. Acute depression of cardiac function by alcohol has been found in nomral individuals ${ }^{14} 15$ and in patients with coronary disease, ${ }^{16}$ while disturbed cardiac function or hypertrophy of the left ventricle has been found in chronic alcoholics without cardiac symptoms. ${ }^{17-19}$ In alcoholics who had abstained for a mean of three years function appeared normal ${ }^{20}$ - suggesting that the pathological changes may be reversible. Matthews and colleagues ${ }^{21}$ have recently reported echocardiographic studies on 22 chronic alcoholics without symptoms of heart disease and 11 with congestive cardiomyopathy, using data from 136 normal persons as controls. They found that all patients with symptoms had increased left ventricular systolic and diastolic dimensions and estimated left ventricular mass. Among the symptomless patients two-thirds showed abnormalities in at least one of the variables studied, the most frequent being an increase in left ventricular mass. In the light of earlier studies on the left ventricle ${ }^{22} 23$ Matthews et al have speculated on the stages through which the ventricle may pass as the result of damage by alcohol before the emergence of the typical picture of congestive cardiomyopathy with a dilated, failing ventricle. For example, mild initial dilatation may be accompanied by an increase in the thickness of the wall, so that the ratio of thickness to internal dimension is increased and function remains normal. Further insult results in more dilatation but less thickening of the wall, so that the ratio becomes slightly decreased. Finally, with further dilatation but no change in wall thickness the stress on the wall increases, systolic function is impaired, and decompensation becomes apparent.

At first glance, echocardiographic studies of this kind may seem simple, but in fact they require time, practice, and accuracy and are not available as a prognostic tool for most of the patients at risk. With alcoholism a growing problem in Britain $^{24}$ alcoholic heart disease may be expected to increase. Physicians must therefore be alert to the diagnosis in any patient who presents with cardiac failure without one of the common underlying pathological causes, especially if atrial fibrillation is present. ${ }^{6}$ We must accept that alcohol is a potential myocardial poison, though the precise biochemical means by which it exerts its toxic effects is not yet clear. For the busy clinician the mechanism is not of paramount importance. His task, so long as man brews alcoholic drinks, must be to make known their dangers to the heart as well as the liver-and to advise abstinence at the first indication of disturbed cardiac function, when the damage may yet be reversed. ${ }^{20} 25$

Consultant Cardiologist,

R W PORTAL

Kingston General Hospital,

Hull HU3 IUR

${ }^{1}$ Ferrans VJ. Alcoholic cardiomyopathy. Am 7 Med Sci 1966;252:89-104.

${ }^{2}$ Regan TJ. Ethyl alcohol and the heart. Circulation $1971 ; 44: 957-63$.

${ }^{3}$ Rossi MA. Alcohol and malnutrition in the pathogenesis of experimental alcoholic cardiomyopathy. 7 Pathol 1980;130:105-16.

4 Wagner PI. Beriberi heart disease. Physiologic data and difficulties in diagnosis. Am Heart $\mathcal{f}$ 1965;69:200-5.

${ }^{5}$ Evans $\mathrm{W}$. The electrocardiogram of alcoholic cardiomyopathy. Br Heart $\mathcal{F}$ $1959 ; 21: 445-56$.

${ }^{6}$ Brigden W, Robinson J. Alcoholic heart disease. Br Med $\mathcal{f} 1964$;ii: 1283-9.
7 Rubin E. Alcoholic myopathy in heart and skeletal muscle. $N$ Engl 7 Med $1979 ; 301: 28-33$.

${ }^{8}$ Hibbs RG, Ferrans VJ, Black WC, Weilbaecher DG, Walsh JJ, Burch GE. Alcoholic cardiomyopathy. An electron microscopic study. $A m$ Heart $\mathcal{7} 1965 ; 69: 766-79$.

${ }^{9}$ Bulloch RT, Pearce MB, Murphy ML, Jenkins BJ, Davis JL. Myocardial lesions in idiopathic and alcoholic cardiomyopathy. Study by ventricular septal biopsy. Am f Cardiol 1972;29:15-25.

"Rubin E, Katz AM, Lieber CS, Stein EP, Puszkin S. Muscle damage produced by chronic alcohol consumption. Am f Pathol 1976;83: 499-515.

${ }^{11}$ Schenk EA, Cohen J. The heart in chronic alcoholism: clinical and pathologic findings. Pathologia et Microbiologia 1970;35:96-104.

12 Regan TJ, Levinson GE, Oldewurtel HA, Frank MJ, Weisse AB, Moschos CB. Ventricular function in noncardiacs with alcoholic fatty liver: role of ethanol in the production of cardiomyopathy. F Clin Invest 1969 48:397-407.

${ }^{13}$ Asokan SK, Frank MJ, Witham AC. Cardiomyopathy without cardiomegaly in alcoholics. Am Heart $\mathcal{7}$ 1972;84:13-8.

${ }^{14}$ Ahmed SS, Levinson GE, Regan TJ. Depression of myocardial contractility with low doses of ethanol in normal man. Circulation 1973 48:378-85.

15 Delgado CE, Fortuin NJ, Ross RS. Acute effects of low doses of alcoho on left ventricular function by echocardiography. Circulation $1975 ; \mathbf{5 1}$ : 535-40.

${ }^{16}$ Conway N. Haemodynamic effects of ethyl alcohol in patients with coronary heart disease. Br Heart $\mathcal{F} 1968 ; 30: 638-44$

17 Spodick DH, Pigott VM, Chirife R. Preclinical cardiac malfunction in chronic alcoholism. Comparison with matched normal controls and with alcoholic cardiomyopathy. N Engl f Med $1972 ; 287: 677-80$.

${ }^{18}$ Levi GF, Quadri A, Ratti S, Basagni M. Preclinical abnormality of left ventricular function in chronic alcoholics. Br Heart 7 1977;39:35-7.

${ }^{19}$ Askanas A, Udoshi M, Sadjadi SA. The heart in chronic alcoholism: a noninvasive study. Am Heart $\mathcal{F} 1980$;99:9-16.

${ }^{20}$ Reeves WC, Nanda NC, Gramiak R. Echocardiography in chronic alcoholics following prolonged periods of abstinence. Am Heart $\mathscr{f}$ $1978 ; 95: 578-83$.

${ }^{21}$ Matthews EC, Gardin JM, Henry WL, et al. Echocardiographic abnormalities in chronic alcoholics with and without overt congestive heart failure. $A m$ f Cardiol $1981 ; 47: 570-8$.

${ }^{22}$ Grossman W, Jones D, McLaurin LP. Wall stress and patterns of hyper trophy in the human left ventricle. $\mathcal{F}$ Clin Invest $1975 ; 56: 56-64$.

${ }^{23}$ Ford LE. Heart size. Circ Res 1976;39:297-303.

${ }^{24}$ Anonymous. Alcoholism: time for action. $B r$ Med $\mathcal{F} 1981 ; 282: 1177-8$.

${ }^{25}$ Demakis JG, Proskey A, Rahimtoola SH, et al. The natural course of alcoholic cardiomyopathy. Ann Intern Med 1974;80:293-7.

\section{Mechanical intestinal obstruction}

Intestinal obstruction is a common and dangerous surgical emergency. About 1750 deaths from this cause are notified each year in England and Wales, of which 750 are due to strangulated external hernias. Some $80 \%$ of these affect the small bowel. ${ }^{1}$

The causes of the common types of intestinal obstruction have changed quite dramatically during the lifetime of today's senior surgeons. In the first three decades of the century strangulated hernias accounted for a high percentage of cases. Since then the incidence has dropped considerably in the Western world, probably because these hernias have been repaired electively with considerable enthusiasm. By contrast, adhesions have become more and more common owing to the enormous increase in the frequency with which abdominal surgery is now being performed. For example, out of nearly 7000 cases of intestinal obstruction in 21 British hospitals during 1925-30, almost half were due to strangulated hernia and only $7 \%$ to adhesions ${ }^{2}$; but in a series of 1252 cases reported in 1955 and operated on during the previous decade the incidence of adhesions had gone up to $31 \%$, whereas hernias accounted for only $10 \%$ of the cases. ${ }^{3}$ Recently Bizer and his colleagues ${ }^{4}$ have reviewed 405 patients in New York 
with mechanical obstruction of the small intestine, of which almost three-quarters were due to adhesions and $8 \%$ to strangulated hernia.

Interestingly, in less developed communities strangulated hernia (particularly inguinal hernia) remains the most common cause of intestinal obstruction-65\% in Benin City, Nigeria, ${ }^{5}$ $75 \%$ in Uganda, ${ }^{6}$ and as much as $78 \%$ in Ghana. ${ }^{7}$ In these series the incidence of adhesions is low and they are often due to intrapelvic sepsis rather than surgery. There are other remarkable examples of geographical variations. For example, volvulus is relatively unusual in Western Europe and North America, yet it is extremely common in Eastern Europe, parts of Eastern and Central Africa, and India. In India tuberculosis of the intestine is relatively common and sometimes presents as obstruction. A surprisingly high incidence of intussusception in both children and young adults has been reported from Ibadan. ${ }^{8}$

Large series of cases show that throughout the Western world $^{9}$ the very high death rate associated with intestinal obstruction-around $26 \%$ of all cases-typical of the 1920 s and 1930 s has now been reduced to about $10-15 \%$. This improvement has undoubtedly been due to a combination of improved anaesthesia, better knowledge of fluid and electrolyte replacement, efficient blood transfusion services, and the introduction of antibiotics. The major factors adversely influencing survival rate are strangulation of the bowel with gangrene (or worse still perforation), delay in treatment with severe distension and gross fluid and electrolyte disturbance, and extremes of age-mortality being especially high in children and the elderly. As recently as 1976, Barnett and his colleagues reported 56 deaths out of 151 cases of intestinal strangulation. ${ }^{10}$

Many thousands of pages have been written by dozens of experienced surgeons on the differential diagnosis of simple and strangulated obstruction. Various authorities have emphasised various factors in the history, the examination, and the results of laboratory investigations of these patients. A sudden onset of pain that is continuous rather than colicky, the early appearance of shock, fever, tachycardia, appreciable abdominal tenderness, release tenderness, guarding, a tender abdominal mass, and a raised white blood count are all said to point to strangulation. Yet close analysis of any series of cases will soon show that attempts at such differential diagnosis are little more than academic. Indeed, most experienced surgeons will point out the very real dangers of attempting such diagnostic accuracy, and advocate early laparotomy as a routine in cases of acute mechanical intestinal obstruction. ${ }^{9}$ Silen and his colleagues, ${ }^{11}$ for example, found that only 17 of 112 cases of strangulated obstruction were correctly diagnosed at the initial admission to hospital. Shatila and colleagues ${ }^{12}$ compared 50 patients with strangulated obstruction with 53 having simple occlusion. The two groups had a similar incidence of pain, vomiting, distension, raised pulse rate and temperature, and tenderness and rebound. A mass was more common in strangulation (including strangulated hernia); and rigidity, shock, a depressed temperature, and rectal bleeding occurred in a few cases of late strangulation. The white blood count (beloved as a differential sign by many authors) was raised above 11000 in 24 of the 53 cases of simple strangulation and 31 of the 50 strangulated cases. Other reports have given similar comparative results. ${ }^{1314}$

No matter how well the patient may seem and how innocent the local and general signs may be, there are no clinical means or any accurate laboratory or radiological tests that will show whether a strangulated loop of intestine, with all its lethal potential, is present within the abdominal cavity. This is perhaps the most vitally important fact the surgeon must bear in mind when he deals with a case of intestinal obstruction. Once a clinical diagnosis of obstruction is made, even when radiological appearances are normal and there is nothing to suggest strangulation, the best treatment is still urgent surgery. Procrastination merely puts the patient's life in further jeopardy.

H Ellis

Professor of Surgery,

Westminster Medical School,

London SW1P 2AP

1 Becker WF. Acute obstruction of the colon. An analysis of 205 cases. Surg Gynecol Obstet 1953;96:677-82.

Vick RM. Statistics of acute intestinal obstruction. Br Med $\mathcal{f} 1932$;ii 546-8.

${ }^{3}$ Wangensteen OH. Intestinal obstructions. 3rd ed. Springfield, Ill: Thomas, 1955.

${ }^{4}$ Bizer LS, Liebling RW, Delany HM, Gliedman ML. Small bowel obstruction. The role of nonoperative treatment in simple intestinal obstruction and predictive ctiteria for strangulation obstruction. Surgery $1980 ; 89$ : 407-13.

${ }^{5}$ Chiedozi LC, Aboh IO, Piserchia NE. Mechanical bowel obstruction. Review of 316 cases in Benin City. Am $\mathcal{F}$ Surg 1980;139:389-93.

${ }^{6}$ McAdam IWJ. A three-year review of intestinal obstruction in Mulago Hospital, Kampala, Uganda. (1958-1960). East Afr Medf 1961 ;38:536-43.

${ }^{7}$ Badoe EA. Pattern of acute intestinal obstruction in Accra. West Afr Med J $1968 ; 17: 194-5$.

${ }^{8}$ Cole GJ. A review of 436 cases of intestinal obstruction in Ibadan. Gut $1965 ; 6: 151-62$

9 Ellis H. Intestinal obstruction. New York: Appleton-Century-Crofts, 1981

${ }^{10}$ Barnett WO, Petro AB, Williamson JW. A current appraisal of problems with gangrenous bowel. Ann Surg 1976;183:653-9.

${ }^{11}$ Silen W, Hein MF, Goldman L. Strangulation obstruction of the small intestine. Arch Surg 1962;85:121-9.

12 Shatila AH, Chamberlain BE, Webb WR. Current status of diagnosis and management of strangulation obstruction of the small bowel. Am $\mathcal{F}$ Surg $1976 ; 132: 299-303$

${ }^{13}$ Becker WF. Acute adhesive ileus. A study of 412 cases with particular reference to the abuse of tube decompression in treatment. Surg Gynecol Obstet $1952 ; 95: 472-6$.

${ }^{14}$ Zollinger RM, Kinsey DL. Diagnosis and management of intestinal obstruction. Am Surg 1964;30:1-5.

\section{Surgical management of syringomyelia}

Painless burns and dissociated anaesthesia in the areflexic wasted arms of a 40-year-old form a distinctive clinical picture of syringomyelia. The disorder is one of the most slowly progressive degenerative diseases of the nervous system; static periods are common, and many patients survive into late middle age after an onset in the 30s. The average age at diagnosis is 45 ; men and women are equally affected. Symptoms have usually been present for five to 10 years at diagnosis, but occasionally they may be traced back to early childhood. A history of protracted labour and birth injury is not uncommon.

The clinical signs are well known, but the stationary periods are less well recognised. Sudden exacerbations of acute syringomyelia may occur after a cough, a sneeze, or sudden straining. Periodic pain in the occipital region and neck may follow such straining and is attributed to stretching of the upper cervical roots by the frequent associated malformation at the foramen magnum with its related hydrodynamic changes.

In most patients a communication, most often a dilated central canal, exists between the fourth ventricle and the 